\title{
Study on the JH-2 Model Parameters for Metro Shield Cutting Reinforced Concrete Pile
}

\section{Ping Xu}

Zhengzhou University

Sixian Zuo ( $\nabla$ zsx1995@qq.com )

Zhengzhou University

\section{Research Article}

Keywords: metro shield, cutting, reinforced concrete pile, JH-2 model, numerical simulation

Posted Date: April 14th, 2021

DOI: https://doi.org/10.21203/rs.3.rs-343050/v1

License: (c) (1) This work is licensed under a Creative Commons Attribution 4.0 International License. Read Full License 


\title{
Study on the JH-2 Model Parameters for Metro Shield Cutting Reinforced Concrete Pile
}

\author{
Ping $\mathrm{Xu}$, Sixian Zuo \\ School of Water Conservancy and Environment, Zhengzhou University, Zhengzhou 450001, P. R. China
}

\begin{abstract}
In order to investigate the application of JH-2 (Johnson-Holmquist-2) constitutive model in concrete, a series of parameters study have been conducted to evaluate the JH-2 model in C30 concrete. The finite element analysis software ABAQUS is utilized to simulate the compression test of the three-dimensional standard concrete test based on the ALE adaptive mesh and the damage failure criterion of element deletion function. The numerical analysis of 3D concrete pile foundation and simplified shield machine cutterhead to simulate shield cutting pile is established. Analyzing the numerical simulation and construction data, the key points of the shield machine cutting pile are illustrated. Research shows that: (1) JH-2 constitutive model can be used to simulate the concrete cutting. (2) The better damage parameters have been represented and verified against the results of experiments, which are the $D_{1}=0.6$ and $D_{2}=0.1$ in the JH-2 model of C30 concrete. (3) In the simulation example of concrete compression and cutting pile, the failure form of concrete is brittle failure, and the non-linear characteristics of concrete has been observed. (4) The simulated torque vibration of the cutterhead is relatively large than actual pile cutting, and the actual shield machine cutting pile construction should have a low rotation speed and low propulsion speed.
\end{abstract}

Key words: metro shield; cutting; reinforced concrete pile; JH-2 model; numerical simulation 


\section{Introduction}

The cutting is a very complex process, which include elastoplastic mechanics, fracture mechanics, thermodynamics and tribology. The changes of internal stress, strain and temperature during the cutting cannot be accurately measured and detailed describe due to the limitation of experimental technology. Therefore, numerical simulation can be used to conduct an effective analysis and research during the cutting(Yan and Chen 2011), and numerical simulation can also avoid too expensive tests, which fully follows the sustainable development in constructions.

Related materials have been used to investigate the cutting in the numerical simulation, which mainly include JC model, D-P model, HJC model, JH-1 model, JHB model, JH-2 model, etc. The JC model is mainly used for metal cutting simulation. The D-P model is often used for rock and soil cutting(Zhu and Jia 2014; Li et al. 2018; Liu et al. 2019). The HJC model is mainly used for the simulation of large deformation and high strain rate of concrete and $\operatorname{rock}($ Holmquist et al. 1993). However, the failure criterion of the HJC model is the equivalent plastic strain failure criterion. This criterion is mainly used to evaluate the compression failure, but it cannot effectively evaluate the failure caused by tension or shear. JH-1, JHB and JH-2 models are often used to simulate the model with large deformation and high strain rate of brittle materials, and can be used for ceramics, rock, concrete and other materials. JH-2(Johnson and Holmquist 1994) is based on JH-1(Johnson and Holmquist 1990) by adding continuous damage and deterioration effect of strength to describe the gradient failure process of the material. However, there are few literatures represented that the JH-2 model is used to cutting concrete. Oucif(Oucif et al. 2020) applies the JH-2 model to concrete. 
But the corresponding parameters of the cited $\mathrm{JH}-2$ model are referred to the original paper(Johnson and Holmquist 1994). This paper intends to analyze and summarize the acquisition method and $\mathrm{JH}-2$ model application in $\mathrm{C} 30$ concrete based on various previous tests, and provides a new idea and the different simulation method for the concrete cutting.

The numerical analysis part of this paper is based on the actual shield cutting plain concrete pile foundation engineering. The shield tunnel is conflict with the existing viaduct pile foundation in the planned route. The construction company uses the method of pile foundation underpinning to build the new pile foundation of viaduct. However, the original pile foundation exists underground in the form of residual piles, which conflicts with the planned tunnel. The construction company originally planned to impact the residual pile below the planned shield tunnel through the method of downward impact. However, considering the complex geological conditions under the viaduct, numerous pipelines, and a complex location, the methods of impacting pile, drilling pile, and pulling pile are all too dangerous. Only the method of cutting pile by shield machine can be used. In order to prevent the shield machine from being unable to rotate on the shield machine cutterhead with the main reinforcement bars twisted during cutting. They drilled the remaining pile to take reinforcement bars and changed the pile foundation into a "beehive coal" form. Then, mortar is poured into the drilled holes, and then the shield machine cutting work is performed. In theory, it is feasible to change reinforced concrete pile into plain concrete pile with reduced strength. The project is feasible.

\section{JH-2 model(Johnson and Holmquist 1994)}

The JH-2 model is suitable for simulating brittle materials, and can be used for 
simulation of ceramics, rocks, concrete, etc. The model analyses are mainly divided into two parts, the strength and the state equation.

\subsection{Strength}

The normalized equivalent stress of the $\mathrm{JH}-2$ model is

$$
\sigma^{*}=\sigma_{i}^{*}-D\left(\sigma_{i}^{*}-\sigma_{f}^{*}\right)
$$

Where $\sigma_{i}^{*}$ is the normalized intact equivalent stress, $\sigma_{f}^{*}$ is the normalized fracture stress, $D$ is the damage factor $(0 \leq D \leq 1.0)$.

The normalized equivalent stress $\left(\sigma^{*}, \sigma_{i}^{*}, \sigma_{f}^{*}\right)$ has following that:

$$
\sigma^{*}=\sigma / \sigma_{H E L}
$$

Where $\sigma$ is the actual equivalent stress and $\sigma_{H E L}$ is the equivalent stress at $H E L$.

The normalized intact strength is given by

$$
\sigma_{i}^{*}=A\left(P^{*}+T^{*}\right)^{n}\left(1+C \ln \varepsilon^{*}\right)
$$

The normalized breaking strength is determined by

$$
\sigma_{f}^{*}=B\left(P^{*}\right)^{m}\left(1+C \ln \varepsilon^{*}\right) \leq S F M A X
$$

The material constants are $A, B, C, m, n$ and SFMAX, where $A$ and $n$ are the complete strength parameters of the material, $B$ and $m$ are the residual strength parameters of the material, and $C$ is the rate parameter of the material. The normalized pressure is $P^{*}=P / P_{H E L}$, where $P$ is the actual pressure and $P_{H E L}$ is the pressure at $H E L$. The normalized maximum tensile hydrostatic pressure is $T^{*}=T / P_{H E L}$, where $T$ is the maximum tensile hydrostatic pressure that the material can withstand. The dimensionless strain rate is $\stackrel{\square *}{*}^{*}=\stackrel{\square}{\varepsilon} / \varepsilon_{0}$, where $\bar{\varepsilon}$ is the actual strain rate and $\bar{\varepsilon}_{0}=1.0 \mathrm{~s}^{-1}$ is the reference strain rate. The strength model curve is shown in Figure 1. 


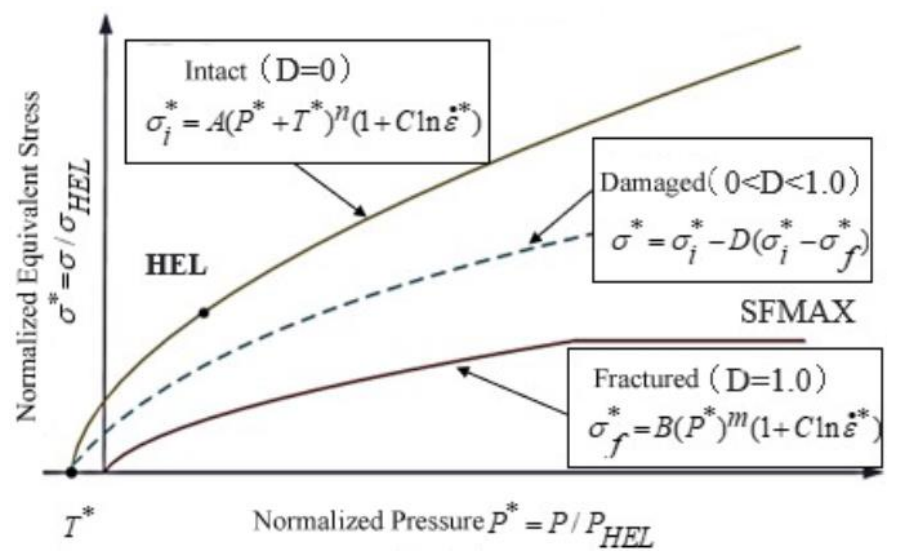

Fig.1 Strength model of the JH-2 model(Johnson and Holmquist 1994)

\subsection{Damage}

The cumulative way of fracture damage is expressed as

$$
D=\sum \frac{\Delta \varepsilon^{p}}{\varepsilon_{f}^{p}}
$$

Where $\Delta \varepsilon^{p}$ is the plastic strain during the integration cycle, and $\varepsilon_{f}^{p}=f(P)$ is the plastic strain at break under a constant pressure $P$. The specific expression is

$$
\varepsilon_{f}^{p}=D_{1}\left(P^{*}+T^{*}\right)^{D_{2}}
$$

Where $D_{1}$ and $D_{2}$ are the damage parameters of $\varepsilon_{f}^{p}$.

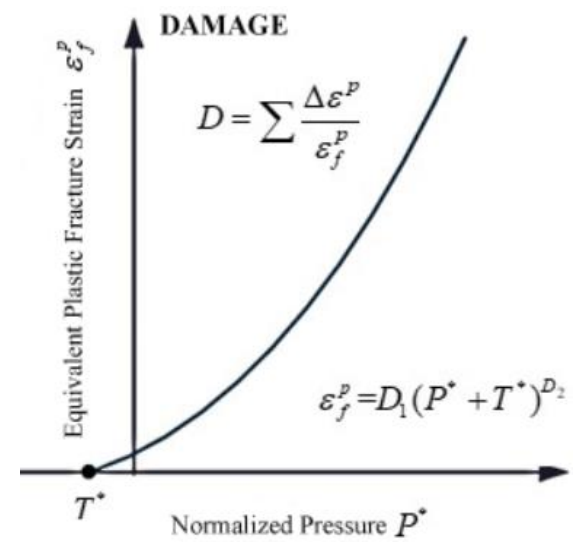

Fig.2 Damage model of the JH-2 model(Johnson and Holmquist 1994)

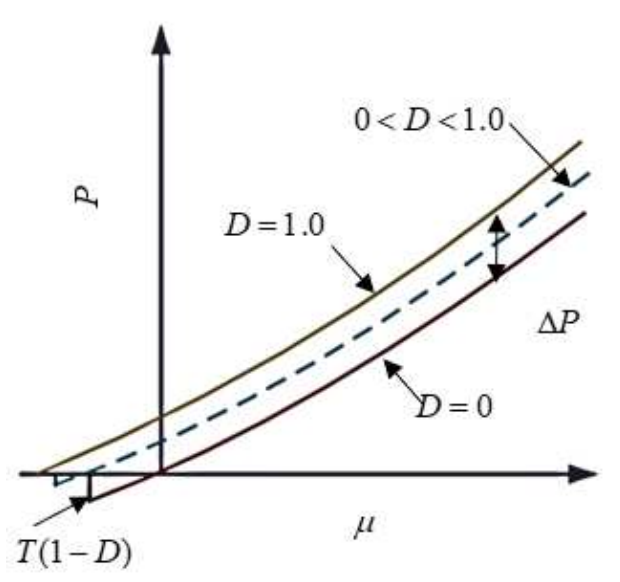

Fig.3 EOS model of the JH-2 model(Johnson and Holmquist 1994)

The physical explanation of damage and fracture is illustrated in Figure 2 and Figure 3.

If the material is held under a constant pressure and then subjected to a straining 
deformation at a constant strain rate, the damage begins to accumulate when the material begins to flow plastically (at $\sigma=\sigma_{i}$ ). Then the material begins to soften relative to its intact strength. This softening may be related to the transition of the material from a larger particle size to a smaller particle size under increased plastic strain. When the material is completely damaged ( $D=1.0)$, the strength doesn't decrease with the increase of plastic strain $\left(\sigma=\sigma_{f}\right)$.

But the material performance cannot be conducted under higher pressure in these tests.

Therefore, the damage function and fracture strength must be inferred from other data.

$$
\left\{\begin{array}{l}
P=K_{1} \square \mu+K_{2} \square \mu^{2}+K_{3} \square \mu^{3}(D=0) \\
P=K_{1} \square \mu+K_{2} \square \mu^{2}+K_{3} \square \mu^{3}+\Delta P(0<D \leq 1)
\end{array}\right.
$$

Equation (7) is the equation of state in Figure 3. When $D=0$, it represents the hydrostatic pressure before the crack starts. When $0<D \leq 1$, damage begins to accumulate and the volume may expand (pressure increase or volumetric strain increase). $\Delta P$ is the pressure increment. Where $K_{1}$ is the bulk modulus, $K_{2}$ and $K_{3}$ are constants; $\mu$ is the volume strain, where $\mu=\rho / \rho_{0}-1, \rho$ is the current density and $\rho_{0}$ is the initial density.

\section{JH-2 model parameter acquisition}

The determining parameters of the JH-2 model in concrete is extremely complicated in the test. The tests include plate impact test, dynamic triaxial test, SPHB test and other related tests. This section focuses on the data summary and fitting of the literature's data that has done corresponding concrete tests in the past, and obtains a set of JH-2 model parameters suitable for concrete.

\subsection{Basic physical parameters}

Tab.1 C30 concrete physical parameters(GB50010-2010 2010)

\begin{tabular}{ccc}
\hline $\begin{array}{c}\text { Elastic Modulus } \\
\mathrm{E}(\mathrm{MPa})\end{array}$ & Poisson's ratio $v$ & $\begin{array}{c}\text { Density } \rho \\
\left(\mathrm{kg} / \mathrm{m}^{3}\right)\end{array}$ \\
\hline 30000 & 0.2 & 2400 \\
\hline
\end{tabular}


Shear modulus $G=\frac{E}{2(1+v)}=12500 M P a$, Bulk modulus $\quad K_{1}=\frac{E}{3(1-2 v)}=16667 M P a$

\subsection{State equation parameters}

The relationship between the volumetric strain of the material and the hydrostatic pressure in the JH-2 model is shown in equation (7). When the material is not broken $(D=$ $0)$, the state equation is

$$
P=K_{1} \sqsubset \mu+K_{2} \square \mu^{2}+K_{3} \square \mu^{3}
$$

$K_{2}$ and $K_{3}$ need to be calculated by curve fitting according to the volume strain and hydrostatic pressure data obtained from one-dimensional strain plate impact test.

The data measured in literature(Wang et al. 2008) are shown in Table 2

Tab.2 Volumetric strain and hydrostatic pressure data

\begin{tabular}{cc}
\hline $\begin{array}{c}\text { Volumetric strain } \\
\mu\end{array}$ & $\begin{array}{c}\text { Hydrostatic pressure } P \\
(\mathrm{GPa})\end{array}$ \\
\hline 0.111396 & 2.4882 \\
0.158275 & 3.47311 \\
0.168474 & 3.72781 \\
0.179883 & 4.04439 \\
\hline
\end{tabular}

Performing nonlinear fitting through equation (8) can get $K_{2}=73.19 \mathrm{GPa}, K_{3}=$ -236.2GPa, $R^{2}=0.9927$. The state curve equation is equation (9), and the fitting curve diagram is shown in Figure 4.

$$
P=16.667 \mu+73.19 \mu^{2}-236.2 \mu^{3}
$$




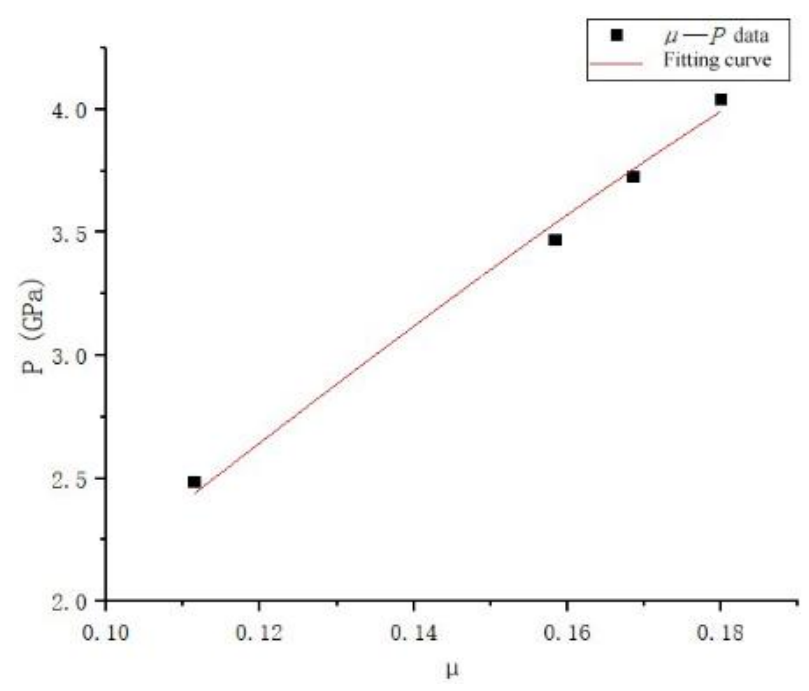

Fig.4 Curve of state equation

\subsection{Intensity-related parameters}

HEL is the Hugoniot elastic limit. Determining the HEL of concrete is more complicated and requires a plate impact test. $H E L$ is based on the concept of static yield under one-dimensional strain. However, the yield stress of materials with one-dimensional strain is very strict to the experimental equipment and conditions. There are few literatures about the determination of $H E L$ in concrete. Rosenberg(Rosenberg 1993) proposed the relationship between the spalling strength of brittle materials and $H E L$ as shown in equation (10).

$$
H E L=\frac{8(1-v)}{(1-2 v)^{2}} \sigma_{\text {spall }}
$$

Where $\sigma_{\text {spall }}$ is the spall strength, and literature(Kipp et al. 1998) took the spall strength of concrete as 30MPa. By formula (10), the concrete HEL $=1481 \mathrm{MPa}$ can be calculated.

$$
\begin{gathered}
H E L=P_{H E L}+\frac{2}{3} \sigma_{H E L} \\
H E L=K_{1} \mu_{H E L}+K_{2} \mu_{H E L}^{2}+K_{3} \mu_{H E L}^{3}+\frac{4}{3} G \frac{\mu_{H E L}}{\mu_{H E L}+1}
\end{gathered}
$$

Putting $H E L, K_{1}, K_{2}$, and $K_{3}$ into equations (11) and (12), the volumetric strain under 
HEL $\mu_{H E L}=0.0419, P_{H E L}=811 \mathrm{MPa}, \sigma_{H E L}=1005 \mathrm{MPa}$.

To determine the parameters $A$ and $n$, a triaxial test of concrete is required. Without considering the strain rate coefficient $C$, the formula (3) can be changed to

$$
\sigma_{i}^{*}=A\left(P^{*}+T^{*}\right)^{n}
$$

The normalized hydrostatic pressure is $P^{*}=P / P_{H E L}$, where the hydrostatic pressure is $P=\frac{\sigma_{1}+\sigma_{2}+\sigma_{3}}{3}$. According to the concrete tensile strength formula $T=0.62 \sqrt{f_{c}}$ proposed by the American Concrete Association, the tensile strength of C30 concrete can be calculated as $3.4 \mathrm{MPa}$, which is $T^{*}=T / P_{H E L}=4.192 \times 10^{-3}$. The normalized equivalent stress is $\sigma^{*}=\sigma / P_{H E L}$ and the stress equivalent is $\sigma=\sqrt{3 J_{2}}=\sqrt{\frac{1}{2}\left[\left(\sigma_{1}-\sigma_{2}\right)^{2}+\left(\sigma_{2}-\sigma_{3}\right)^{2}+\left(\sigma_{3}-\sigma_{1}\right)^{2}\right]}$.

By sorting out the concrete dynamic triaxial data in the literature(Yan et al. 2007; Li et al. 2011; Yi et al. 2020), the relationship between the equivalent stress and the hydrostatic pressure under different confining pressures is calculated, and through the nonlinear fitting of equation (13), $A=0.6304, n=0.8437, R^{2}=0.9909$. The fitting curve is shown in Figure 5 .

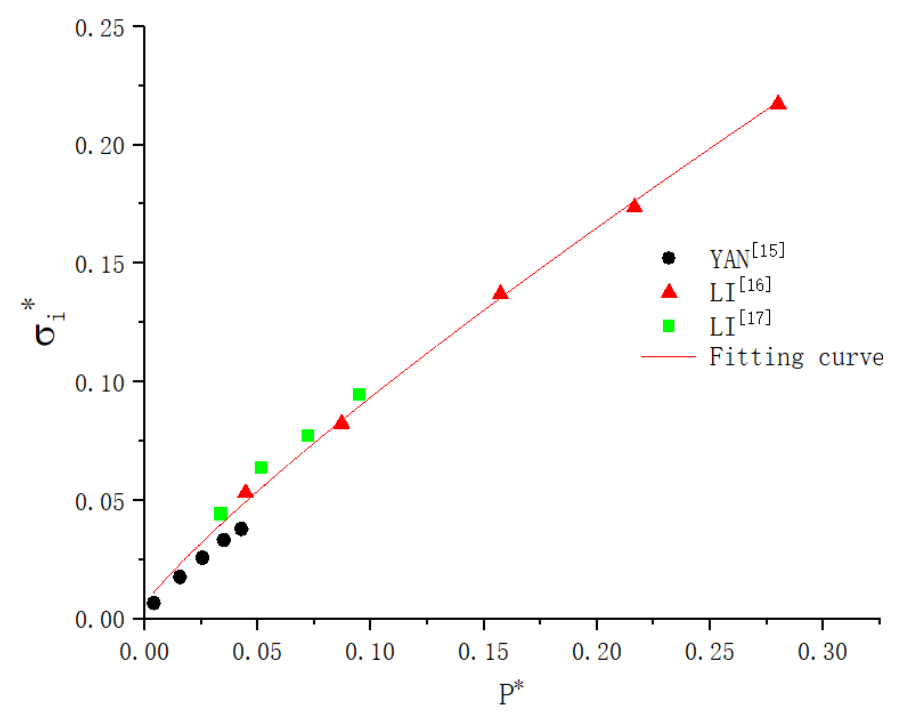

Fig.5 Curve of strength equation 
Banadaki(Banadaki and Mohanty 2012) believes that due to the lack of information on the residual strength after destruction, parameter $B$ is considered to be $1 / 3$ of parameter $A$, and parameter $m$ is assumed to be the same as parameter $n$, then $B=0.2101$ and $m=0.8437$ can be taken.

\subsection{Rate parameter}

The strain rate parameter $C$ is equal to the parameter $C$ in the HJC model, and the parameter $C$ needs to be determined based on the SHPB test. Literature(Genmao et al. 2016) makes a linear fitting of the equivalent stress after eliminating the influence of hydrostatic pressure at different natural logarithmic strain rates of various kinds of concrete, and obtain $C=0.006$.

\subsection{Damage parameters}

The initial values of the damage parameters $D_{1}$ and $D_{2}$ are taken as $D_{1}=0.04$ and $D_{2}=$ 1.0 provided in the literature(Johnson and Holmquist 1994). The transition from intact strength to complete failure strength is described by the damage factor $D$. The plastic strain of brittle materials with complete failure is very small and impossible to measure directly, leading to the failure of damage parameters $D_{1}$ and $D_{2}$. On the contrary, reliable values of $D_{1}$ and $D_{2}$ can be obtained by numerical simulation trial adjustment to achieve acceptable damage effect. In this paper, by simulating the compressive strength test of standard concrete test blocks to obtain the parameters. The concrete test block of $150 \mathrm{~mm} \times 150 \mathrm{~mm} \times 150 \mathrm{~mm}$ is established. $D_{1}$ is $0.1,0.2,0.3,0.4,0.5,0.6,0.7,0.8,0.9,1.0$, and $D_{2}$ is $0.1,0.2,0.3,0.4,0.5,0.6,0.7,0.8,0.9,1.0$. Combining the above values to simulate the compression test of 100 sets of concrete standard test blocks, the optimal damage effect data is obtained: $D_{1}=0.6, D_{2}=0.1$. The results of the failure stress and 
equivalent plastic strain of the simulated test block are shown in Figures 6 and 7, and the failure cracks are "X" shape.

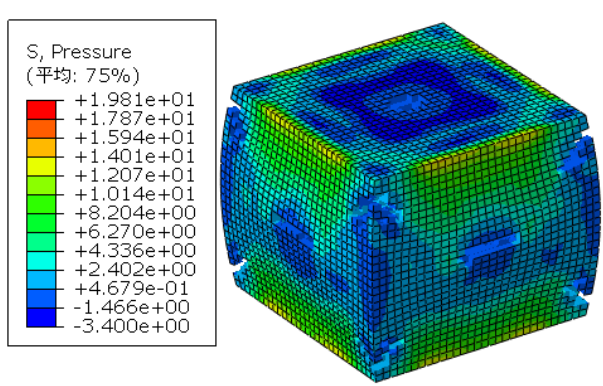

Fig.6 Standard concrete test block failure stress nephogram (MPa)

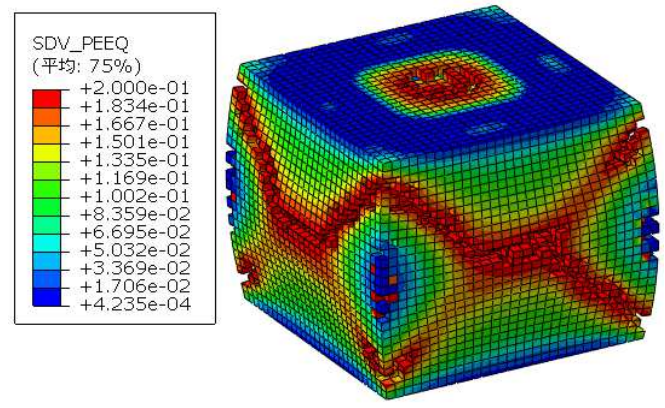

Fig.7 Standard concrete test block failure PEEQ nephogram

In summary, the data simulated in this paper are shown in Table 3:

Tab.3 C30 concrete JH-2 parameters

\begin{tabular}{|c|c|c|c|c|c|}
\hline$\rho /\left(\mathrm{kg} \cdot \mathrm{m}^{-3}\right)$ & $G / \mathrm{MPa}$ & $A$ & $B$ & $n$ & $C$ \\
\hline 2400 & 12500 & 0.6304 & 0.2101 & 0.8437 & 0.006 \\
\hline$m$ & $\varepsilon_{0}$ & $T / \mathrm{MPa}$ & $D_{1}$ & $D_{2}$ & $H E L / G P a$ \\
\hline 0.8437 & 1 & 3.4 & 0.6 & 0.1 & 1.481 \\
\hline$K_{1} / \mathrm{GPa}$ & $K_{2} / \mathrm{GPa}$ & $K_{3} / \mathrm{GPa}$ & \multicolumn{2}{|c|}{$P_{H E L} / \mathrm{GPa}$} & \\
\hline 16.667 & 73.19 & -236.2 & \multicolumn{2}{|c|}{0.811} & \\
\hline
\end{tabular}

\section{Numerical analysis of cut piles}

In order to investigate the application of the $\mathrm{JH}-2$ model in concrete, a numerical analysis case of cutting pile foundation by the shield machine cutterhead is established according to the actual engineering. The pile foundation concrete is C30 concrete with a diameter of $1.5 \mathrm{~m}$ and a length of $18 \mathrm{~m}$. The cutterhead for cutting pile foundation is composite cutterhead. The cutter for shield machine cutterhead includes common cutter, disc cutter, advance cutter, profiling cutter, etc. And their excavation methods are cut, scratch and crush. The working method of the cutter is mainly by rotation of the cutterhead, the blade exerts pressure on the soil, when the soil reaches the ultimate failure stress, shear deformation occurs, and the chips are discharged. The disc cutter is suitable for rock, and its 
working method is that the blade directly faces the rock. When the blade cuts into the rock, a compression core is demonstrated in the crushing zone. The compaction core further forms are radioactive cracks on the rock and gradually forms rock fragments. Therefore, the disc cutter is also suitable for crushing brittle materials such as concrete, but the disc cutter is not suitable for cutting steel bars in reinforced concrete pile. When the disc cutter works in soft soil, the disc cutter will be collapsed due to the jam blocked. The advance cutter is to disturb the soil before cutting, which is more conducive to the work of the cutting tool. The profiling cutter is to create the required space for over excavation.

\subsection{Pretreatment}

Appropriate simplifications were made in the numerical simulation modeling due to the limitation of computer performance. Therefore, the disc cutters, advance cutters and profiling cutters are all removed, and corbel of the cutterhead is also removed. Keep the common cutter and center cutter of the cutterhead, and set it as a rigid body for calculation. The diameter of the cutterhead is $6200 \mathrm{~mm}$. The width of common cutter is $180 \mathrm{~mm}$, which is $150 \mathrm{~mm}$ higher than the cutterhead. And the front and rear angles are $10^{\circ}$. The length of center cutter is $830 \mathrm{~mm}$ and the width of center cutter is $100 \mathrm{~mm}$, which is $330 \mathrm{~mm}$ higher than the cutterhead. The models of common cutter, center cutter and overall cutterhead are shown in Figure 8 10.

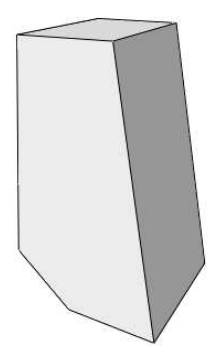

Fig.8 Common cutter model

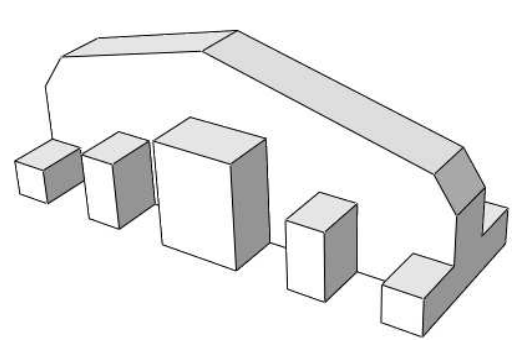

Fig.9 Center cutter model

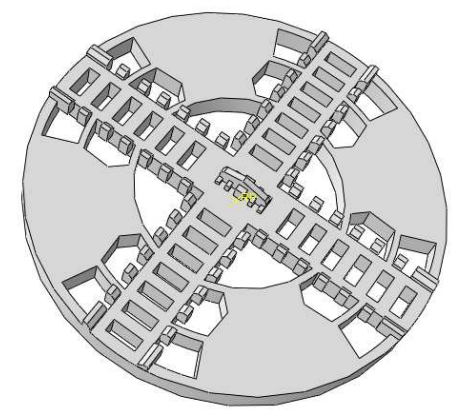

Fig.10 Shield machine cutterhead model 
The concrete of pile foundation is $\mathrm{C} 30$, and the relevant parameters of the $\mathrm{JH}-2$ model are distributed. The parameters are shown in Table 1 and 3. The cutter material is tungsten carbide cemented carbide, the elastic modulus is $652 \mathrm{GPa}$, the Poisson's ratio is 0.22 , and the density is $15700 \mathrm{~kg} / \mathrm{m}^{3}$.

The assembly is based on the actual project, and the position of the shield machine is located in the center of the pile. The mesh of the pile foundation is set to a hexahedral mesh, and the middle part of the cut pile is closed to ensure the accuracy of the calculation. Due to the complex structure of the cutterhead, the cutterhead mesh can only be set to a tetrahedron. The assembly and meshing are shown in Figure 11. Set the non-cutting parts of the upper and lower sides of the pile body to be encastre. The ALE adaptive mesh is used for the pile, and the damage failure criterion of the element deletion function is applied to delete the damaged element.

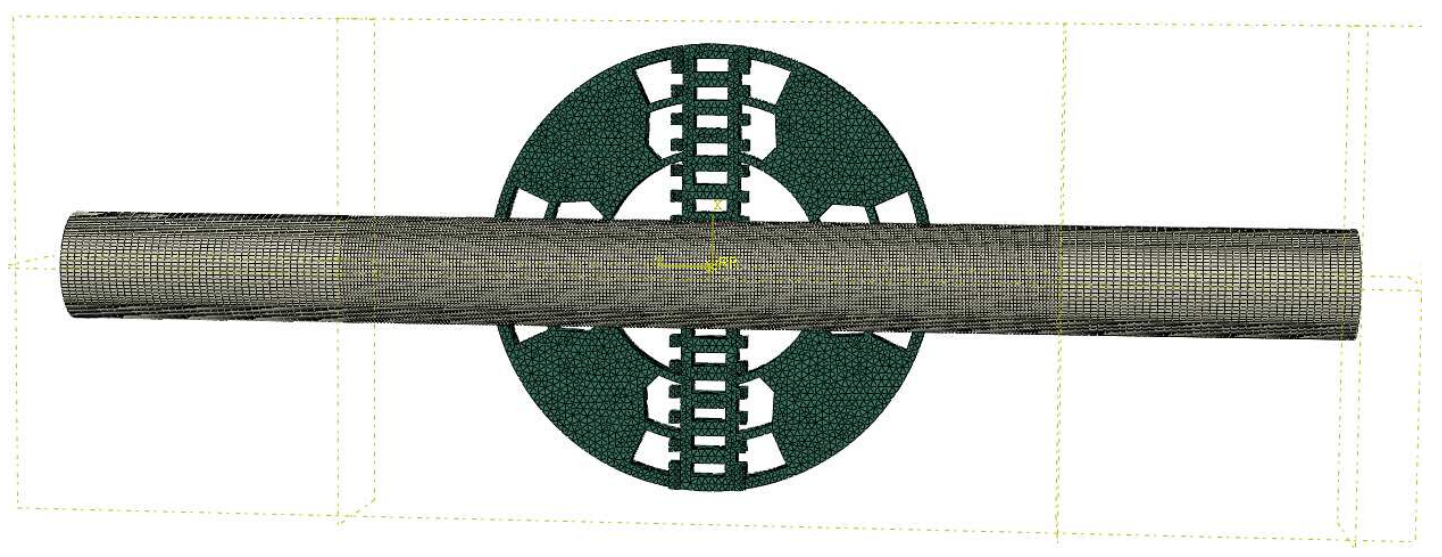

Fig.11 Assembly and mesh

\subsection{Calculation results and analysis}




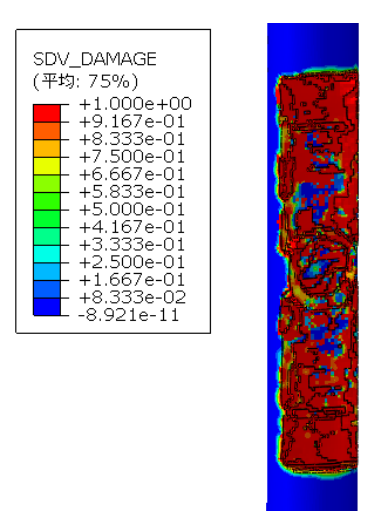

Fig.12 Damage

Nephogram
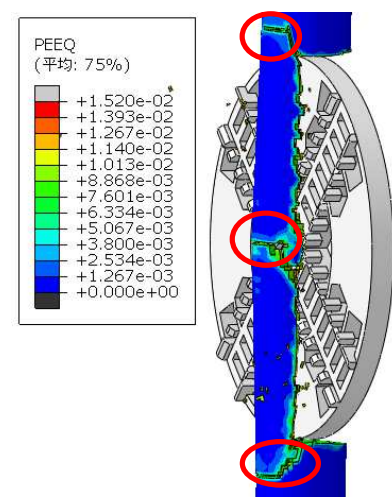

Fig.15 PEEQ Nephogram when cracking develops

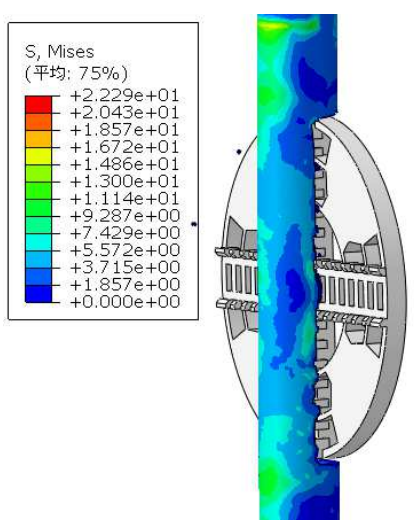

Fig.13 Mises

Nephogram(MPa)

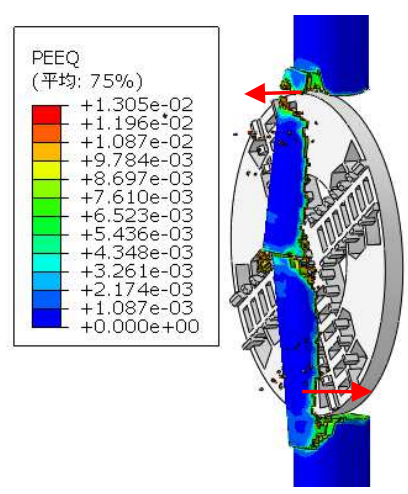

Fig.16 PEEQ Nephogram of final cracking
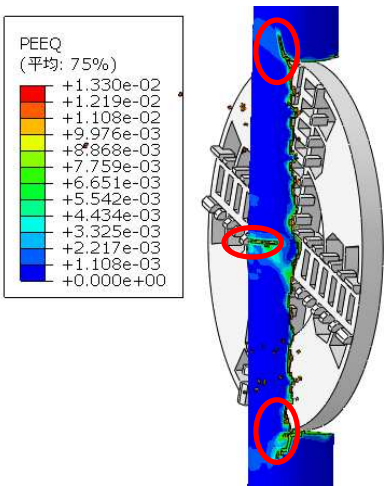

Fig.14 PEEQ Nephogram at the beginning of cracking

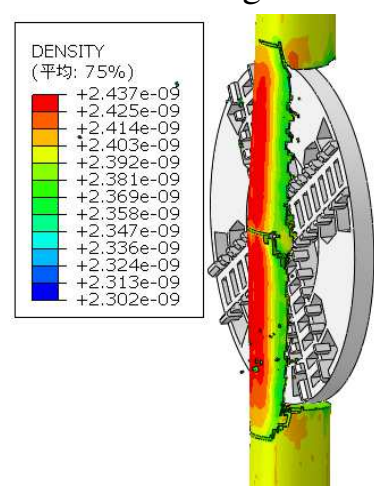

Fig.17 Density

nephogram(tonne/mm3)

The damage nephogram of the pile in the process of cutting is shown in Figure 12.

When the damage reaches to 1 , the element reaches the maximum load bearing capacity and will be deleted. The Mises stress state during pile cutting is shown in Figure 13. The "red circle" in Figures 14 is the large strain of the pile when the pile is cut, which explains the cracking trend of the component. The crack development process during pile cutting is shown in the "red circles" in Figures 14 and 15. When cutting to $1100 \mathrm{~mm}$, cracks occurred on the upper and lower sides of the pile and same to the center of the pile. The cracks on the upper and lower sides are generated during the propulsion of the cutterhead and are mainly affected by the thrust of the cutterhead. The middle crack is caused by the rotation of the center cutter, which is mainly caused by the rotation of the cutterhead when the cutterhead is 
thrusted. As shown in Figure 15, the crack penetrated the pile body when it was cut to 1270mm, and the overall crack occurred. The final fracture result is shown in Figure 16. The fragments are divided into two large fragments under the action of the rotation of the cutterhead, and the moving direction of the fragments is consistent with the linear velocity direction of the rotation direction of the cutterhead. Figure 17 shows the density state of the pile when the pile is cut. This method can more intuitively show the tension, compression, and shear states of the pile. In this paper, the concrete density of the numerical simulation is set to $2400 \mathrm{~kg} / \mathrm{m}^{3}$. As shown in the Figure 17 , the concrete in contact zone with the cutterhead is less dense in the last fragment, while the other side that is not in contact is larger. This is mainly due to the cutterhead damage to the concrete pile for shear failure. Under the action of shear, the concrete density of this part is lower than the extruded part outside. It also proved that the compressive strength of concrete is stronger than the shear strength. This is mainly because the damage of concrete pile by the cutterhead is shear damage. Under the action of shear, the density of this part of the concrete is lower than that of the outer squeezed part. It is demonstrated that the compressive capacity of concrete is stronger than the shear capacity.

Figure 18 is the broken line diagram of the cutterhead torque when cutting pile. When cutting starts, the center cutter of the cutterhead contacts the surface of the pile foundation at first. Because the center cutter is partly higher than the common cutter, the initial cutting torque is lower. When the cutterhead continues to thrust and the common cutters cut the pile, the cutterhead torque has a significant increase. Due to the advance cutter is removed in the process of modeling, some of the common cutters are no longer stressed after the common 
cutters cut the pile, resulting the cutterhead torque drop suddenly. Figure 14 shows a state where the torque vibrates violently. When the crack starts to develop, the torque peak of the cutterhead is lower than the previous part, and the amplitude is reduced. When the cutterhead thrusts to the penetration crack of the pile, the torque of the cutterhead decreases again and gradually tends to a relatively stable state. The broken concrete pieces are shown in Figure 16.

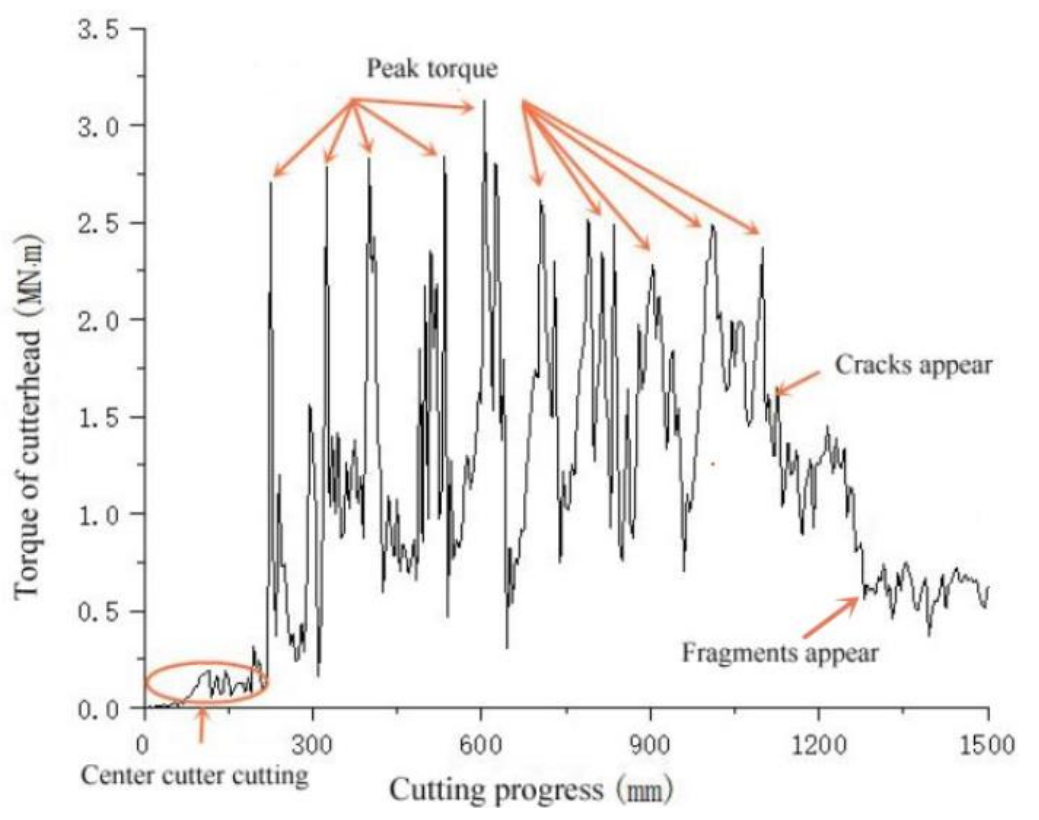

Fig.18 Cutterhead torque line

\section{Construction analysis}

The shield machine used for pile cutting is Herrenknecht S-716, and the cutterhead of the shield machine is a composite cutterhead, as shown in Figure 19. The rated torque of the main drive of the shield machine is $5835 \mathrm{kN} \cdot \mathrm{m}$, and the relief torque is $6807 \mathrm{kN} \cdot \mathrm{m}$. Figure 20 shows the working parameters of Herrenknecht S-716. The drilling core construction is shown in Figure 21, and the core sample is shown in Figure 22. 


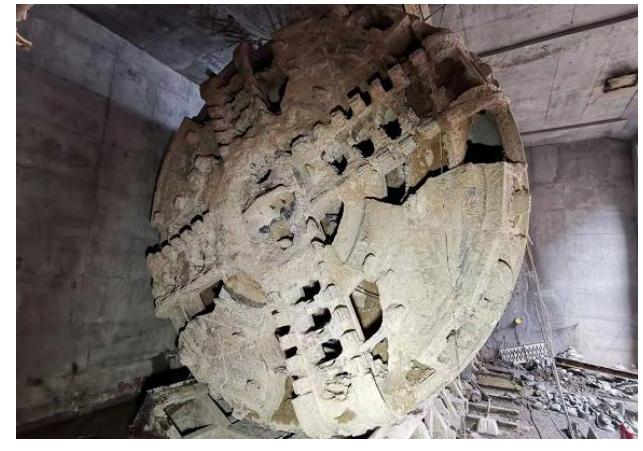

Fig.19 Herrenknecht S-716

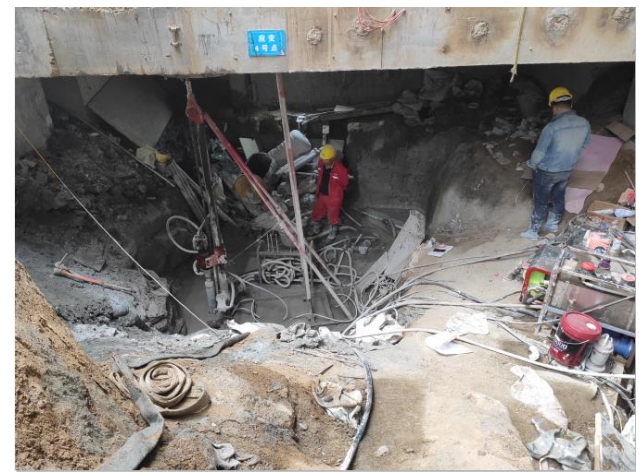

Fig.21 Drilling and coring construction

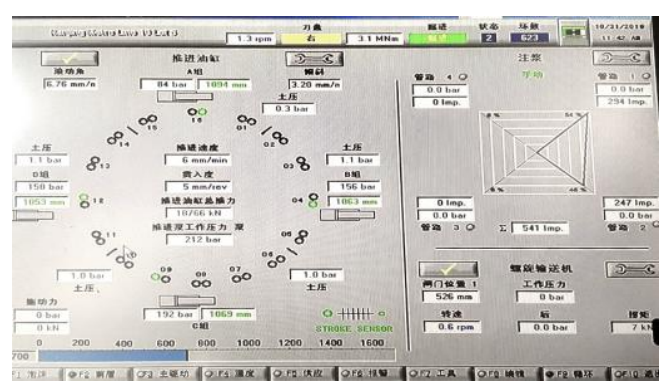

Fig.20 Tunneling parameters

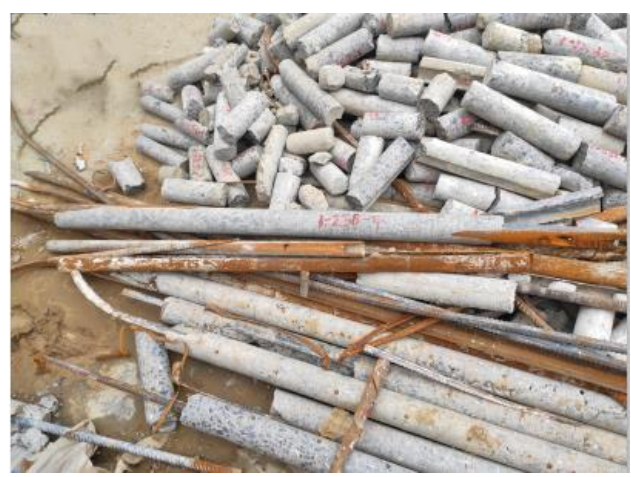

Fig.22 Drilling core samples

The tunneling torque of shield machine includes cutting torque, rotary resistance torque of the cutterhead, counterforce torque generated by thrust load on cutterhead, friction torque generated by the sealing device, friction torque on the front face of the cutterhead, friction torque behind the cutterhead, shear torque of the cutterhead opening, and stirring torque in the soil silo(Guan and Gao 2008). Because of muck conditioning technology, the torque of the cutterhead can be greatly reduced in soft soil excavation. The total torque obtained is an approximate theory without considering the muck conditioning technology. However, considering the muck conditioning technology and the large amount of foam in the actual pile cutting construction, most of the shield machine torque is provided by the cutterhead cutting pile. The cutterhead torque of the shield machine collected on site is shown in Figure 23. 
During pile cutting, the maximum torque is $3.7 \mathrm{MN} \cdot \mathrm{m}$, which shows that the cutterhead is stuck. Due to incomplete cleaning of the steel bars, the steel bars could not be cut by the cutter, but the cutterhead penetration is large, and the steel bar is wound around the cutterhead. If the cutterhead continues to rotate without stopping, it may cause excessive torque and shut down the shield machine. The site is successfully freed by reversing the cutterhead. And the discharged steel bar is shown in Figure 24.

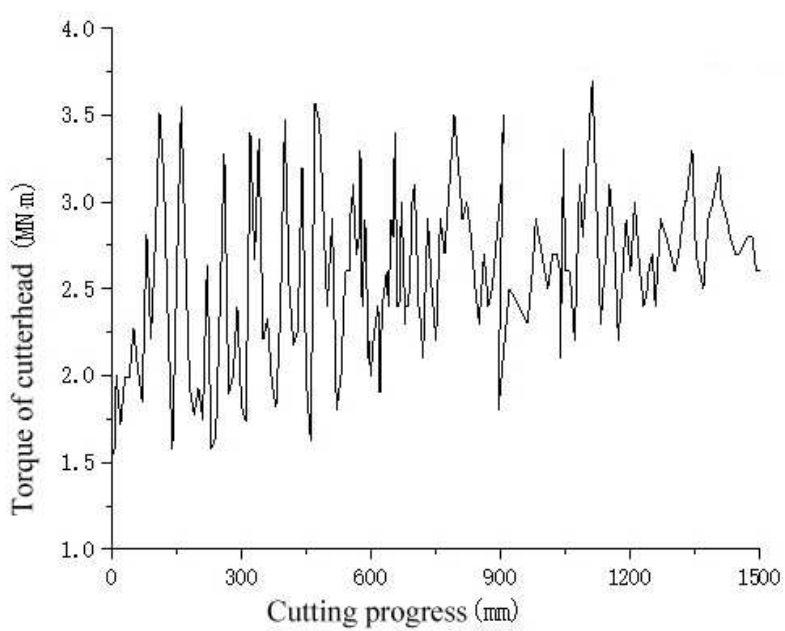

Fig.23 Cutterhead torque line

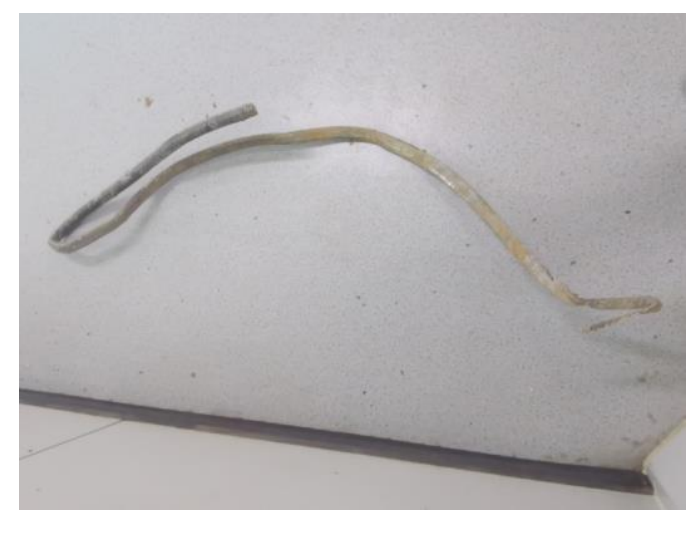

Fig.24 Residual rebar

Table 4 shows the mathematical statistics of the simulation cutting torque and actual construction cutting torque.

Tab.4 Mathematical statistics of simulation torque and construction torque

\begin{tabular}{ccccc}
\hline $\begin{array}{c}\text { Working } \\
\text { condition }\end{array}$ & $\begin{array}{c}\text { Average } \\
\text { value } \\
(\mathrm{MN} \cdot \mathrm{m})\end{array}$ & $\begin{array}{c}\text { Maximum } \\
(\mathrm{MN} \cdot \mathrm{m})\end{array}$ & $\begin{array}{c}\text { Minimum } \\
(\mathrm{MN} \cdot \mathrm{m})\end{array}$ & $\begin{array}{c}\text { Standard } \\
\text { deviation } \\
(\mathrm{MN} \cdot \mathrm{m})\end{array}$ \\
\hline Simulation & 1.089 & 3.128 & 0.003 & 0.704 \\
Construction & 2.578 & 3.7 & 1.5 & 0.474 \\
\hline
\end{tabular}

Depending on the data comparison in Table 4, the numerical simulation torque results are relatively small compared to the construction torque, but the standard deviation of the simulation results is large. In other words, the cutting torque is scattered and unstable. The 
main reason is that the simulated cutterhead only retains the common cutter and the center cutter, and only simulates the working conditions of the cutterhead for pile cutting, ignoring the interaction between the cutterhead and the soil, and other torques. However, instability of cutting can easily cause damage to the cutterhead. In the actual construction, the shield machine should reduce the rotation speed and the propulsion speed to further reduce the damage of the shield machine cutter.

\section{Conclusion}

Based on the collection and summary of concrete impact damage related tests in previous literatures, the parameters of $\mathrm{JH}-2$ model of $\mathrm{C} 30$ concrete are calculated in this paper. The finite element software ABAQUS is utilized to simulate the failure of the three-dimensional standard concrete test blocks and simulate the pile cutting test by shield machine cutterhead.

The conclusions are as follows:

(1) JH-2 constitutive model can be used to simulate the concrete cutting.

(2) The better damage parameters have been represented and verified against the results of simulations, which are the $D_{1}=0.6$ and $D_{2}=0.1$ in the JH-2 model of C30 concrete.

(3) In the simulation example of concrete compression and cut pile, the failure form of concrete is brittle failure, and the non-linear characteristics of concrete has been observed.

(4) The simulated torque vibration of the cutterhead is relatively large than actual pile cutting, and the actual shield machine cutting pile construction should have a low rotation speed and low propulsion speed. 


\section{Author contribution statement}

Ping Xu: Investigation - editing and supervision. Sixian Zuo: Writing, editing - data analysis and original drafts.

\section{Data availability statement}

The data supporting the results of this study can be obtained from the corresponding author upon reasonable request.

\section{Conflict of interest statement}

The authors do not have any possible conflicts of interest.

\section{References}

Banadaki M, Mohanty B (2012) Numerical simulation of stress wave induced fractures in rock. International Journal of Impact Engineering s 40 - 41:16-25

GB 50010-2010 (2010) Code for design of concrete structures. China Architecture \& Building Press

Genmao R, Hao W, Qin F, Jianwei Z, Ziming G (2016) Determinations of HJC constitutive model parameters for normal strength concrete. Journal of Vibration and Shock 35:9-16

Guan H, Gao B (2008) Theoretical model for estimation of cutter head torque in shield tunneling. Journal of Southwest Jiaotong University 43:213-217

Holmquist TJ, Johnson GR, Cook WH (1993) A Computational Constitutive Model for Concrete Subjected to Large Strains, High Strain Rates and High Pressures. In:14th International symposium, Vol 2; Warhead mechanisms, terminal ballistics; BALLISTICS -INTERNATIONAL SYMPOSIUM-; Vol 2; Warhead mechanisms, terminal ballistics, 1993-01-01, Arlington, Quebec; Canada.ADPA, pp 591-600 
Johnson GR, Holmquist TJ (1990) A computational constitutive model for brittle materials subjected to large strains, high strain rates and high pressures. Shock-Wave and High-Strain-Rate Phenomena in Materials:1075-1081

Johnson GR, Holmquist TJ (1994) An Improved Computational Constitutive Model for Brittle Materials. High Pressure Sci. Technol. 309

Kipp M, Chhabildas L, Reinhart W (1998) Elastic shock response and spall strength of concrete. AIP Conference Proceedings 429:557-560

Li G, Wang W, Jing Z, Zuo L, Wang F, Wei Z (2018) Mechanism and numerical analysis of cutting rock and soil by TBM cutting tools. Tunnelling and Underground Space Technology 81:428-437

Li Q, Xu J, Xiong Y, Yazhou L, Ping W, Ganglin L, Lin Z (2011) Experimental study on concrete strength and deformation characteristics under high confining pressure. Building Structure:85-88

Liu W, Qian X, Li T, Zhou Y, Zhu X (2019) Investigation of the tool-rock interaction using Drucker-Prager failure criterion. Journal of Petroleum Science and Engineering $173: 269-278$

Oucif C, Kalyana RJS, Shankar RK, Abed F (2020) Damage modeling of ballistic penetration and impact behavior of concrete panel under low and high velocities. Defence Technology

Rosenberg Z (1993) On the Relation Between the Hugoniot Elastic Limit and the Yield Strength of Brittle Materials. Journal of Applied Physics - J APPL PHYS 74:752-753

Wang YG, Zhang YP, Wang LL (2008) Experimental study on the shock Hugoniot 
relationship and the Grüneisen-type equation of state for C30 concrete. Acta Physica Sinica -Chinese Edition- 12:7783-7793

Yan D, Lin G, Xu P (2007) Dynamic strength and deformation of concrete in triaxial stress states. Gongcheng Lixue/Engineering Mechanics 24:58-64

Yan Y, Chen Y (2011) 3D numerical simulation of metal cutting processes using a thermomechanical coupled approach. Journal of Mechanical Strength 33:845-849

Yi L, Hua C, Liangliang Z (2020) Energy analysis of C60 concrete under triaxial compression under different confining pressures. Chinese Journal of Applied Mechanics 37:2086-2093

Zhu X, Jia YJ (2014) 3D mechanical modeling of soil orthogonal cutting under a single reamer cutter based on Drucker - Prager criterion. Tunnelling and Underground Space Technology 41:255-262

Corresponding author: Sixian Zuo

Email: zsx1995@qq.com

TEL: +86 17639402258

Address: School of Water and Environment of Zhengzhou University, Kexue Road 100\#, Zhengzhou, Henan Province P.R. China

Zip code: 450001 
Figures

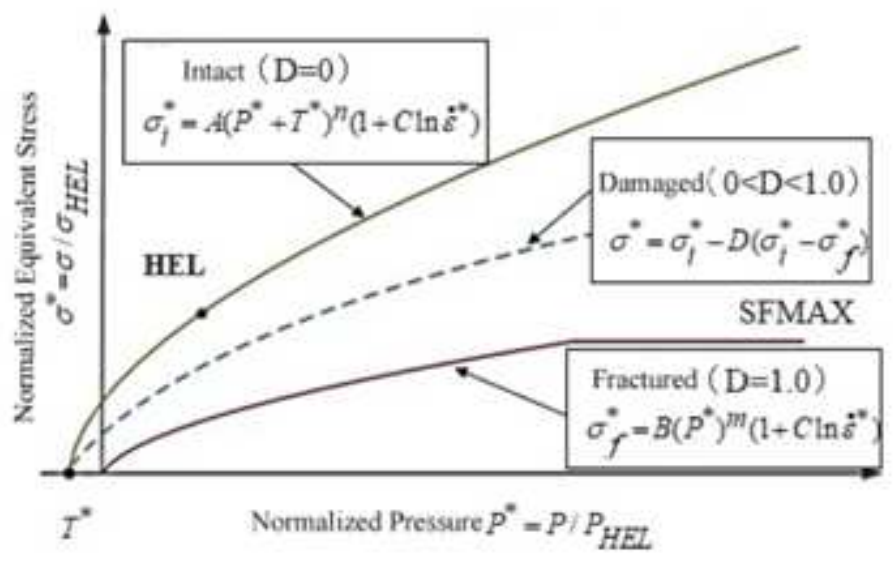

Figure 1

Strength model of the JH-2 model(Johnson and Holmquist 1994)

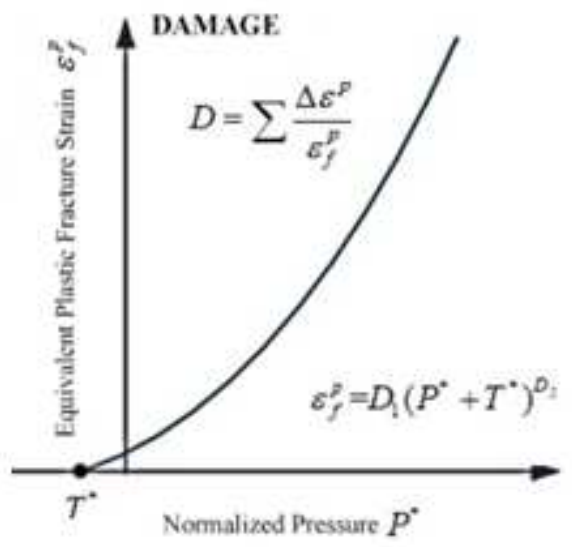

Figure 2

Damage model of the JH-2 model(Johnson and Holmquist 1994)

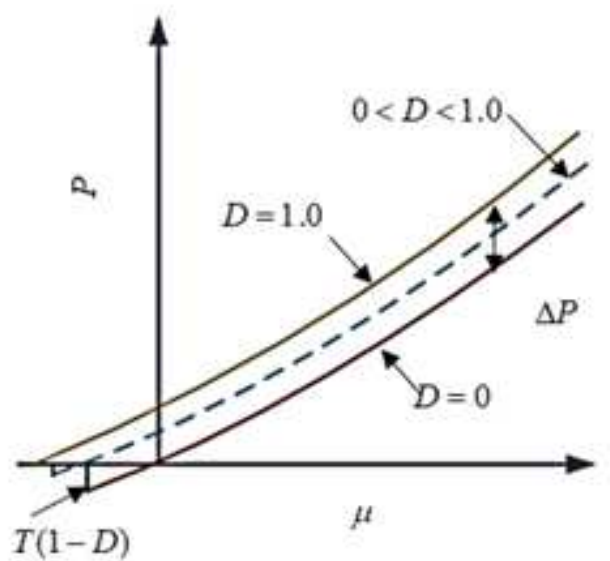

Figure 3 
EOS model of the JH-2 model(Johnson and Holmquist 1994)

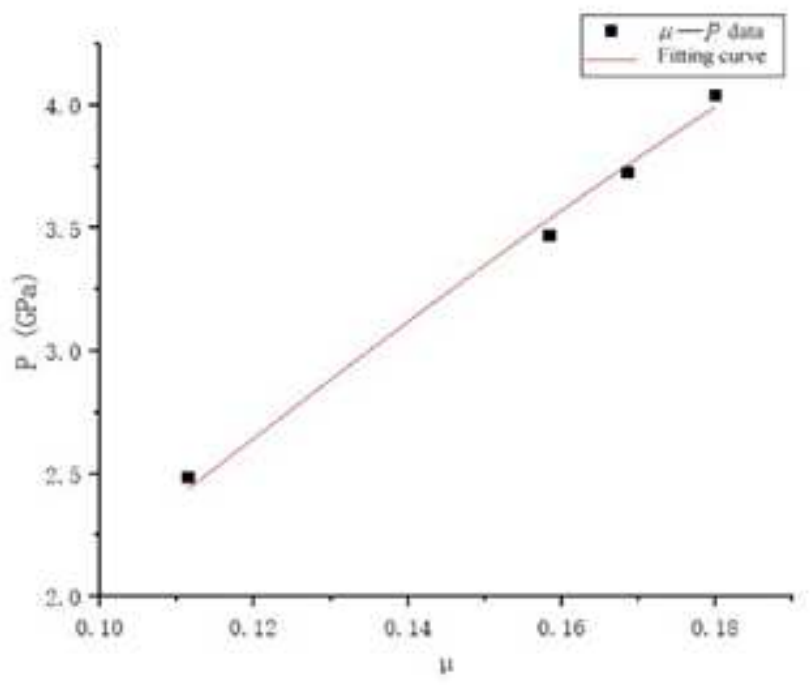

Figure 4

Curve of state equation

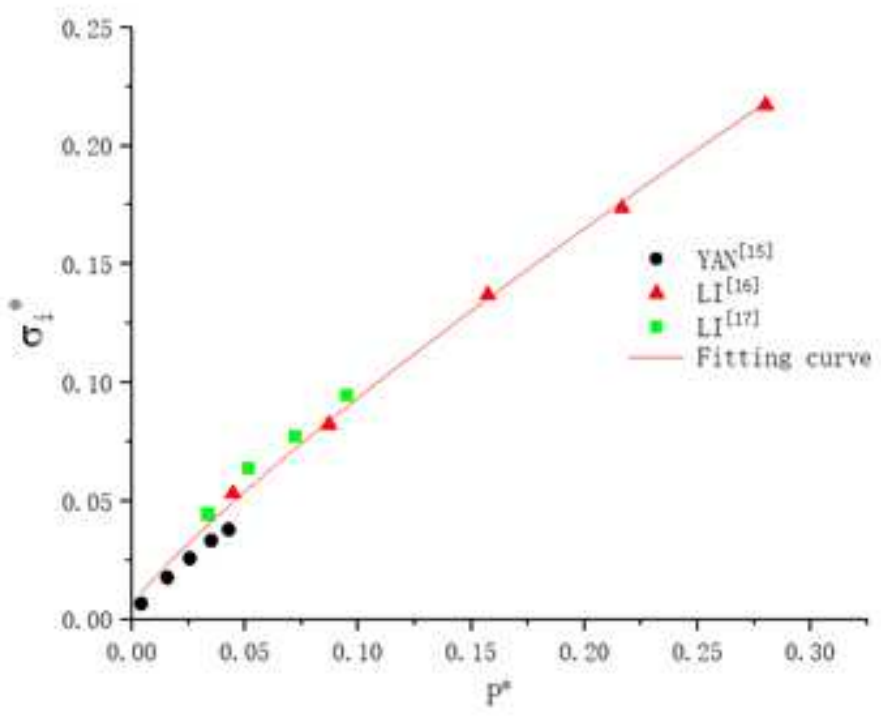

Figure 5

Curve of strength equation

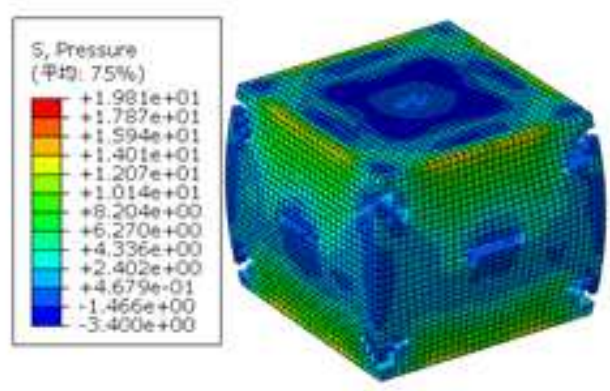


Figure 6

Standard concrete test block failure stress nephogram (MPa)
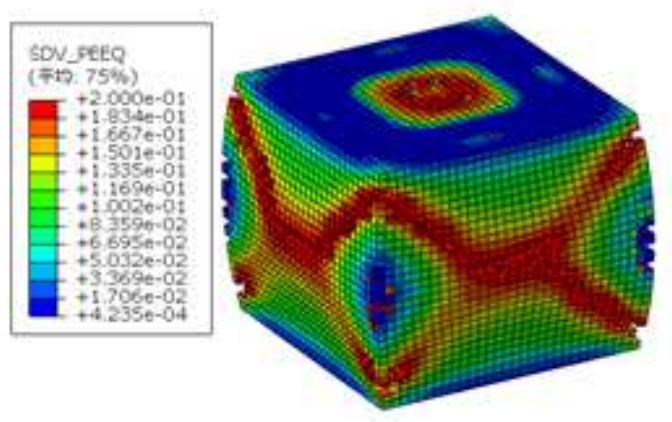

Figure 7

Standard concrete test block failure PEEQ nephogram

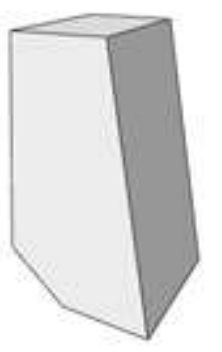

Figure 8

Common cutter model

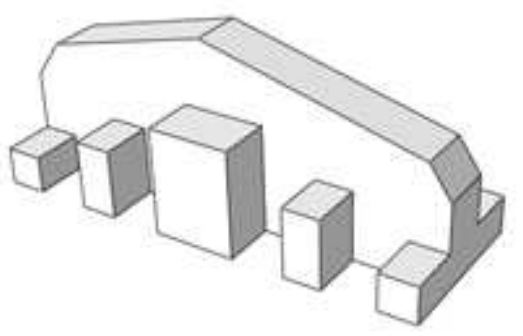

Figure 9

Center cutter model 


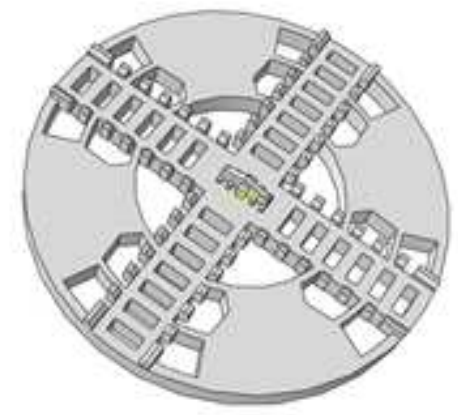

Figure 10

Shield machine cutterhead model

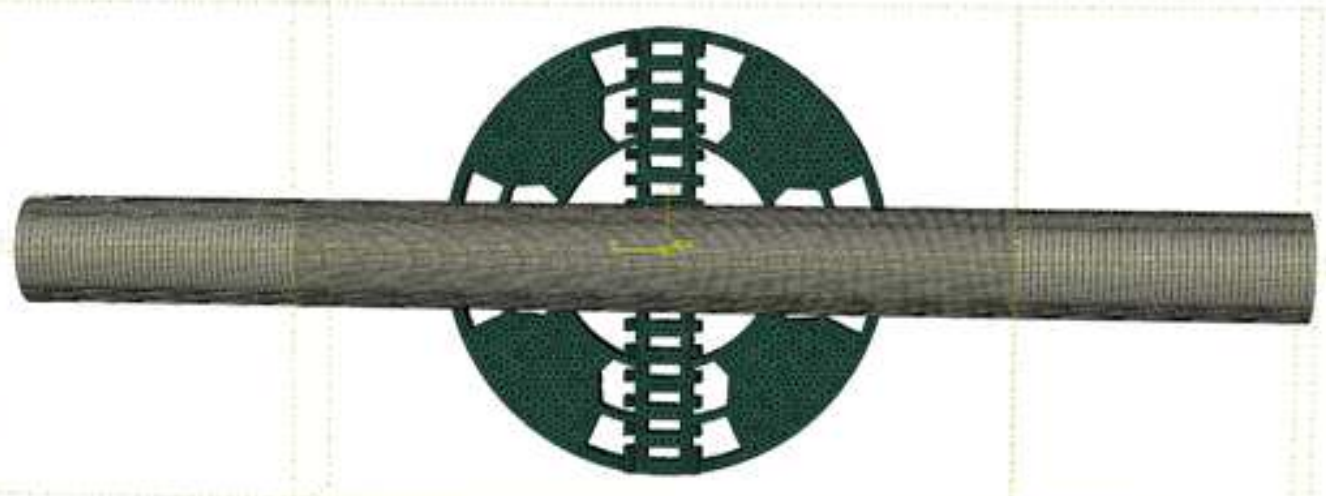

\section{Figure 11}

Assembly and mesh

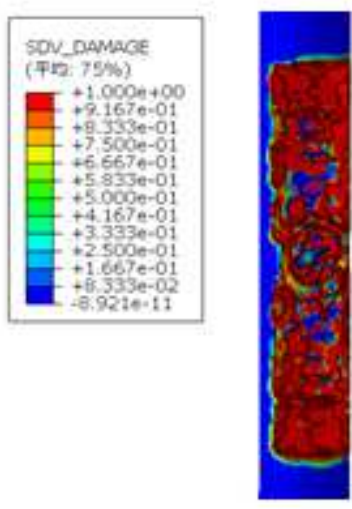

Figure 12

Damage Nephogram 


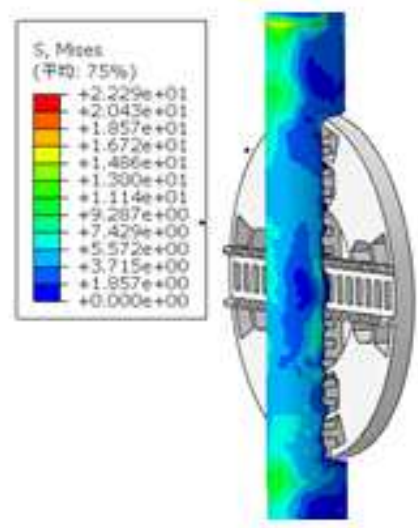

Figure 13

Mises Nephogram(MPa)

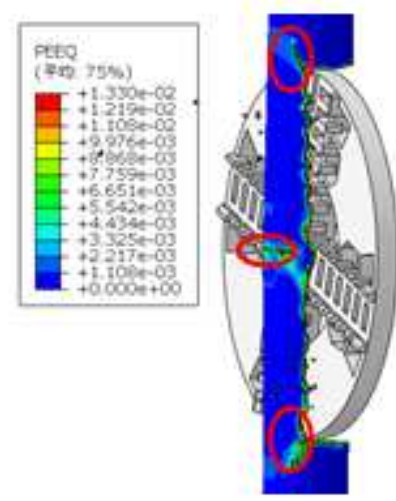

\section{Figure 14}

PEEQ Nephogram at the beginning of cracking

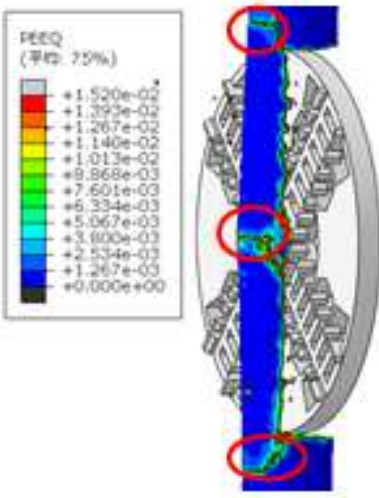

Figure 15

PEEQ Nephogram when cracking develops 


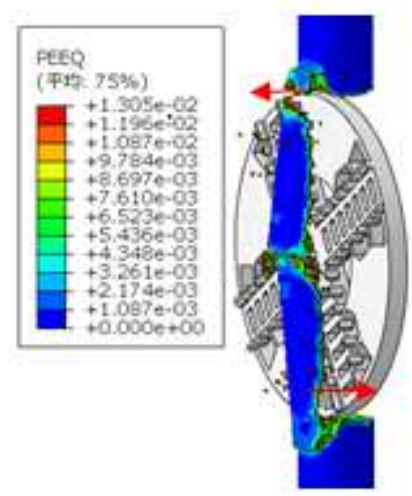

Figure 16

PEEQ Nephogram of final cracking

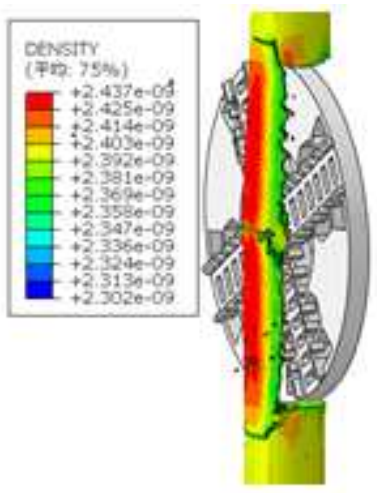

\section{Figure 17}

Density nephogram(tonne/mm3)

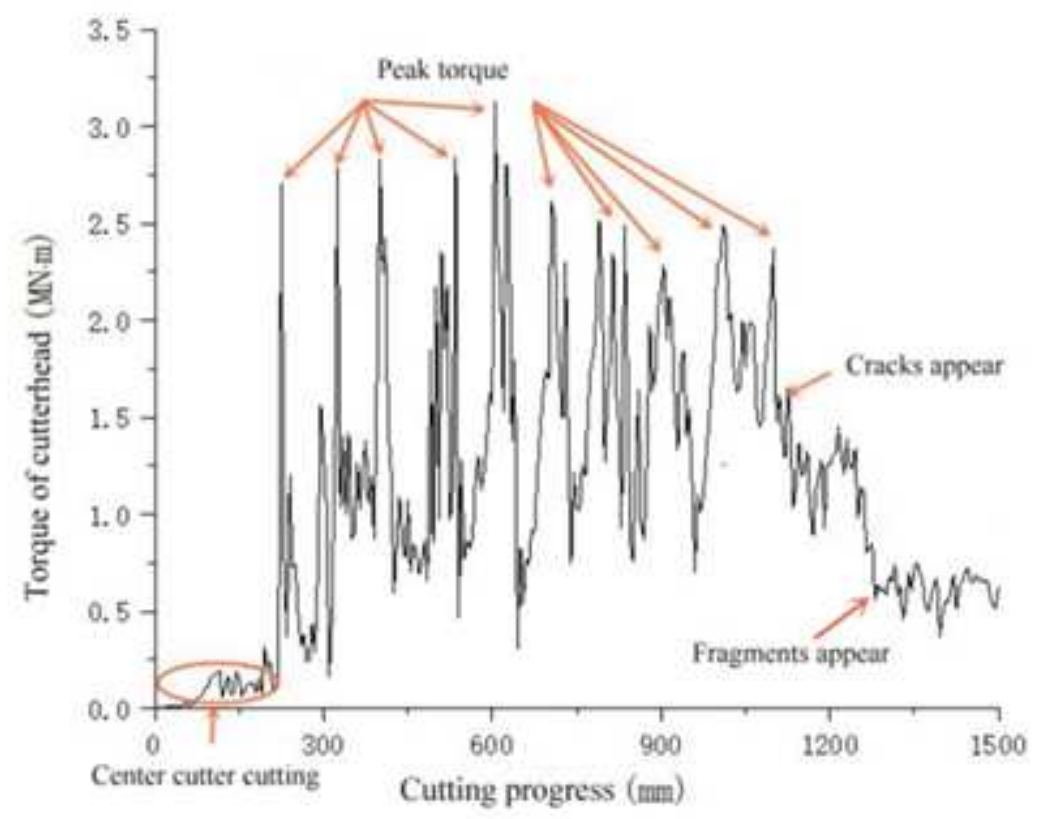

Figure 18 
Cutterhead torque line

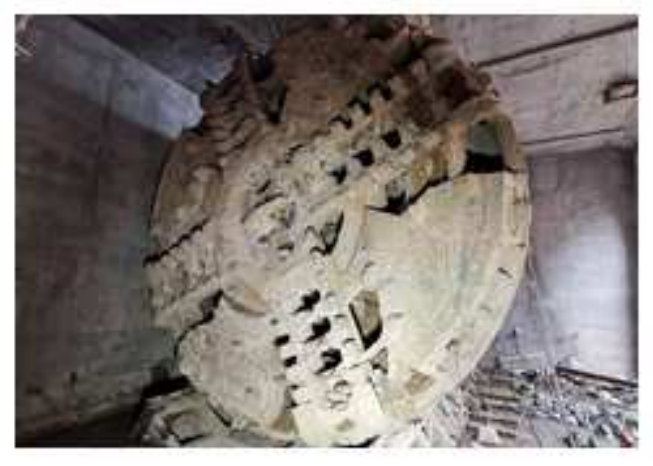

Figure 19

Herrenknecht S-716

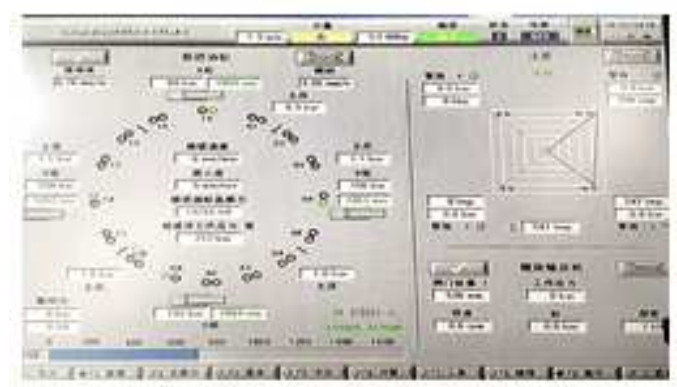

Figure 20

Tunneling parameters

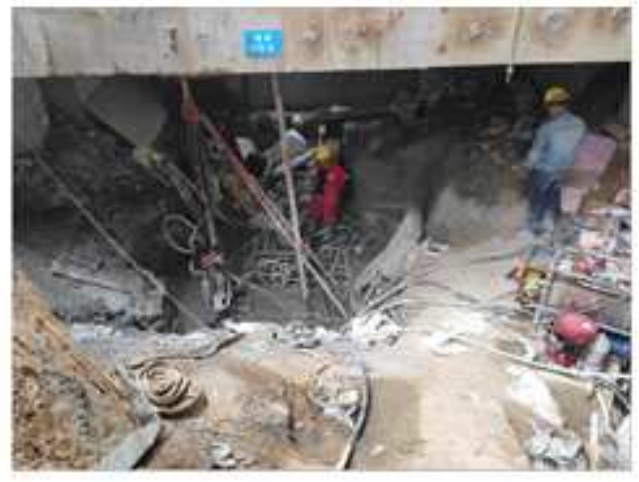

Figure 21

Drilling and coring construction 


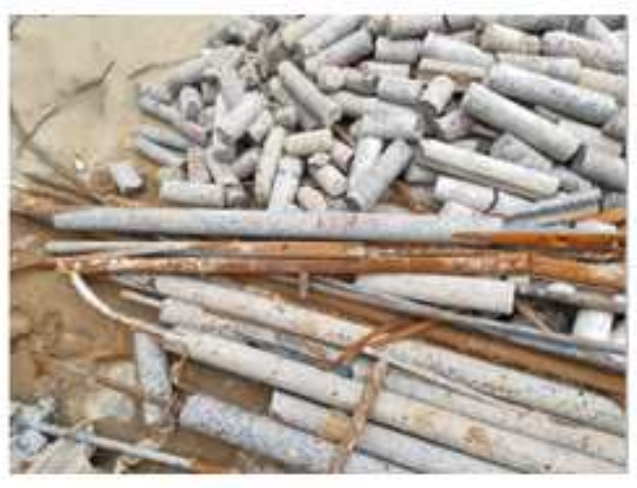

Figure 22

Drilling core samples

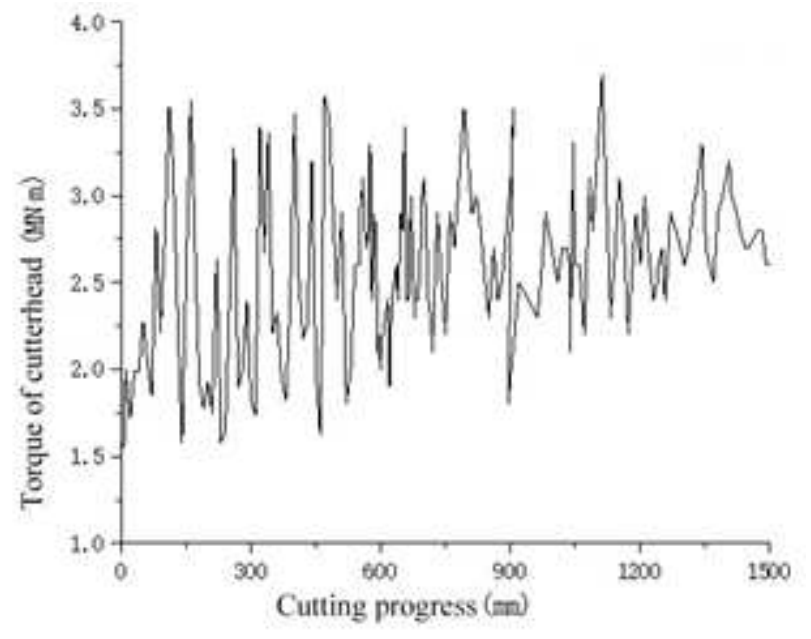

Figure 23

Cutterhead torque line

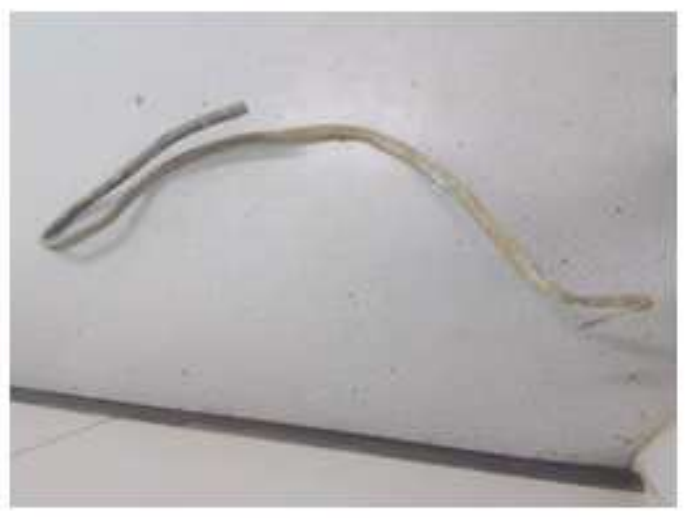

Figure 24

Residual rebar 